\section{AB0901 PREVALENCE OF OSTEOPOROSIS IN ITALIAN POSTMENOPAUSAL WOMEN ACCORDING TO DEFRA ALGORITHM}

A. M. Lurati ${ }^{1}$, A. Laria ${ }^{1}$, L. Castelnovo ${ }^{2}$, P. Faggioli ${ }^{2}$, A. Tamburello ${ }^{2}$, A. Mazzone ${ }^{2} .{ }^{1}$ Rheumatology Unit Fornaroli Hospital Magenta Italy, Magenta, Italy; ${ }^{2}$ Internal Medicine Unit, Ospedale Civile, Legnano, Italy

Background: Osteoporosis is a recognized health problem and the burden of the disease is mostly associated with the occurrence of hip and vertebral fracture. Objectives: This study was aimed at evaluating the prevalence of osteoporosis in Italian postmenopausal women, defined by DeFRA calculation as a 10 years fracture risk equal or higher than $20 \%$.

Methods: This is a monocenter cohort study evaluating 1850 post-menopausal women aged 50 years and older. All the participants were evaluated as far as anthropometrics. Defra questionnaire was administered and calculated with bone mineral density (DXA) measured at lumbar spine and femoral neck.

Results: The prevalence of osteoporosis as assessed by DeFRA was $29.8 \%$ in the whole population, according to literature. The frequency of a risk fracture equal or higher than $20 \%$ varied from $7.9 \%$ in the group aged $50-59$ years to $35 \%$ in subjects aged $>80$. Among clinical risk factors for fracture, the presence of a previous fracture (spine primarily) was the most commonly observed.

Conclusion: Our data showed that about one third of post-menopausal women aged 50 and older in Italy has osteoporosis on the basis of DeFRA algorithm, with a high 10 years fracture risk. A previous fracture is the most common risk factor. The data should be considered in relation to the need to increase prevention strategies and therapeutic intervention.

Disclosure of Interests: None declared

DOI: 10.1136/annrheumdis-2020-eular.3821

\begin{tabular}{|l|l|}
\hline AB0902 & BONE HEALTH IN PATIENTS WITH JUVENILE ONSET \\
DERMATOMYOSITIS ASSESSED AFTER LONG-TERM \\
FOLLOW-UP; A CASE CONTROL STUDY
\end{tabular}

H. Marstein ${ }^{1,2,3}$, K. Godang $^{4}$, B. Flatø $\varnothing^{3,5}$, I. Sjaastad ${ }^{1,3,6}$, J. Bollerslev $^{3,4}$, H. Sanner ${ }^{2,5}$. Institute for Experimental Medical Research and KG Jebsen Center for Cardiac Research, Oslo University Hospital, Ullevål, Oslo, Norway; ${ }^{2}$ Bjørknes University College, Oslo, Norway; ${ }^{3}$ Faculty of Medicine; University of Oslo, Oslo, Oslo, Norway; ${ }^{4}$ Dept of Endocrinology, Oslo University Hospital, Rikshospitalet, Oslo, Norway; ${ }^{5}$ Dept of Rheumatology, Oslo University Hospital, Rikshospitalet, Oslo, Norway; ${ }^{6}$ Dept of Cardiology, Oslo University Hospital, Ullevål, Oslo, Norway

Background: Patients with juvenile dermatomyositis (JDM) are at risk of developing low bone mineral density (BMD) and not reach peak bone mass, mainly due to prednisolone (pred) treatment [1], making them prone to osteoporotic fractures later in life

Objectives: To compare BMD in longterm JDM patients (Pts) with that of controls (Ctr); and in Pts explore how disease variables affect BMD.

Methods: Pts ( $n=59)$ were clinically examined median 16.8y (range $6.6-27.0$ y) after disease onset and compared 1:1 with age/sex matched Ctr. Dual-energy $X$-ray absorptiometry (DXA) was used to measure BMD and Z-scores in whole body (WB), lumbar spine at L2-L4 (spine). In those $\geq 20 y$; also proximal (PR) and distal $1 / 3$ radius (DR), and total hip were examined. Pred at follow up was reported, and cumulative dose calculated. Bone remodeling factors: C-terminal telopeptide (CTX), amino-terminal propeptide (P1NP) and 25(OH)Vitamin D $($ VitD), were measured in serum.

Results: BMD WB was lower in Pts than Ctr, and both WB and spine BMD and $Z$ scores were lower in Pts than Ctr $<20$ years (Tbl 1). DR BMD and $Z$-score were both lower in Pts $\geq 20 y$. Serum analysis showed lower VitD was lower in Pts than Ctr. In Pts $\geq 20 y$ Vit D was lower and eSR was higher compared to Ctr.

In Pts $\geq 20 y$ : moderate negative associations were found between both BMD WB and spine, and pred use at follow up (R`s = -0.43), and between BMD PR and $\operatorname{VitD}(R=-0.34)$. There was a positive moderate association between $Z$-score $P R$ and CTX $(-0.45)$ not found in Ctr, and between Z-score total hip and cumulative pred dose $(R=0.38)$. All $p<0.05$.

In Pts <20y moderate negative associations were found between Z-score for spine and months of pred use and cumulative pred doses $(R ` s=-0.40$ and $-0.48, p<0.05)$. Other associations found in Pts $<20 y$ were also found in respective $\mathrm{Ctr}$.

Conclusion: We found that Pts bone health was affected differently in young and adult JDM-Pts. Association analysis between BMD, Z-scores and medication and/or bone remodeling factors were not conclusive. We will perform linear regression analysis to determine if and how BMDs and Z-scores are dependent on pred use, time and doses, and factors important for bone remodeling.
Table 1. Characteristics, disease variables, BMD and Z-scores in JDM Pts and Ctr

\begin{tabular}{|c|c|c|c|c|c|c|}
\hline & $\begin{array}{c}\text { Pts } \\
(n=59)\end{array}$ & $\begin{array}{c}\text { Pts }<20 y \\
\quad(n=28)\end{array}$ & $\begin{aligned} & \text { Pts } \geq 20 y \\
&(n=31)\end{aligned}$ & $\begin{array}{c}\text { Ctr } \\
(n=59)\end{array}$ & $\begin{array}{c}\text { Ctr }<20 y \\
(n=28)\end{array}$ & $\begin{array}{c}\text { Ctr } \geq 20 y \\
(n=31)\end{array}$ \\
\hline Age, y & $\begin{array}{c}21.5 \\
(6.7-55.4)\end{array}$ & $\begin{array}{c}15.3 \\
(6.7-19.8)\end{array}$ & $\begin{array}{c}34.3 \\
(20.4-55.4)\end{array}$ & $\begin{array}{c}21.6 \\
(6.2-55.4)\end{array}$ & $\begin{array}{c}14.4 \\
(6.2-20.1)\end{array}$ & $\begin{array}{c}34.2 \\
(20.5-55.4)\end{array}$ \\
\hline Female & $36(61)$ & $20(71.4)$ & $16(51.6)$ & $36(61)$ & $20(71.4)$ & $16(51.6)$ \\
\hline $\mathrm{BMI}, \mathrm{kg} / \mathrm{m}^{2}$ & $22.3(4.8)$ & $20.3(4.6)$ & $24.0(4.4)$ & $22.7(4.5)$ & $21.4(5.2)$ & $23.9(3.5)$ \\
\hline Height, cm & $164.9(14.7)$ & 157.1 (15.9) & $171.8(9.1)$ & $167.3(15.8)^{*}$ & * 159.8 (18.3) & $174.0(9.2)$ \\
\hline \multicolumn{6}{|l|}{ BMD, $\mathrm{g} / \mathrm{cm}^{2}$} & NA \\
\hline Whole body & $1.10(0.15)$ & $1.01(0.13)$ & $1.18(0.10)$ & $1.13(0.14)^{\star}$ & $1.06(0.16) \dagger$ & $1.19(0.08)$ \\
\hline Spine, L2-L4 & $41.12(0.23)$ & $0.99(0.21)$ & $1.24(0.18)$ & $1.17(0.22)$ & $1.07(0.27) \dagger$ & $1.26(0.11)$ \\
\hline Distal radius & & NA & $0.87(0.09)$ & & NA & $0.93(0.11) \dagger \dagger$ \\
\hline \multicolumn{7}{|l|}{ Z-score } \\
\hline Whole body & $-0.07(1.08)$ & $-0.39(0.99)$ & $0.21(1.10)$ & $0.27(0.90)$ & $0.28(1.01) \dagger \dagger$ & $0.26(0.71)$ \\
\hline Spine, L2-L4 & $4-0.16(1.2)$. & $-0.39(1.01)$ & 0.06 & $0.4(1.02)$ & $0.25(1.21) \dagger$ & $0.24(0.84)$ \\
\hline Distal radius & & NA & $-0.76(1.03)$ & & NA & $-0.05(0.87)^{\star *}$ \\
\hline
\end{tabular}

y: years, BMI: Body mass index, NA: not applicable. Values are: median age (range), median (IQR), $n(\%)$ or mean (SD). $p$-values ${ }^{*} p<0.05,{ }^{* *} p<0.01$ when comparing Pts and Ctr and $\dagger$ $p<0.05$, $†+p<0.01$ when comparing Pts and $\mathrm{Ctr}<$ and $\geq 20$ years.

\section{References:}

[1] Stewart, W.A., et al., Bone mineral density in juvenile dermatomyositis: assessment using dual $x$-ray absorptiometry. Arthritis Rheum, 2003. 48(8): $p$. 2294-8.

Words: 3555

Disclosure of Interests: None declared

DOI: 10.1136/annrheumdis-2020-eular.5357

\begin{tabular}{l|l}
\hline AB0903 & VITAMIN D LEVELS IN PRIMARY CARE AND \\
RHEUMATOLOGY PATIENTS
\end{tabular}

H. D. Marta ${ }^{1}$, A. García Dorta ${ }^{1}$, C. Luis Zárate ${ }^{1}$, S. Bustabad ${ }^{1}$, F. DiazGonzalez ${ }^{1}{ }^{1}$ Hospital Universitario de Canarias, San Cristóbal de La Laguna, Spain

Background: Although many studies are calling into question the benefits commonly attributed to the vitamin $\mathrm{D}$ out of the bone sphere, in the recent years its determination and supplementation has been generalized in the population Causes of this trend are not clear, but generalist media pressure or even specialized over patients and doctors, along with overrated normality levels could be contributing to this fact. Actual literature ${ }^{123}$ indicates that $25-\mathrm{OH}$ vitamin $\mathrm{D}$ levels of $30 \mathrm{ng} / \mathrm{ml}$ or higher are not necessary, and most of the authors agree that $20 \mathrm{ng} /$ $\mathrm{ml}$ levels are enough for the general population, and only levels below $12.5 \mathrm{ng} / \mathrm{ml}$ must be considered deficient and subsidiaries of supplementation.

Objectives: Obtain the vitamin D levels distribution from a sample of individuals with no bone pathology, or supplementation prescription in Tenerife's North Area Methods: Retrospective descriptive study of the $25-\mathrm{OH}$ vitamin $\mathrm{D}$ levels requests from the Tenerife's North Area, made for any reason by the Primary Care Doctor or the rheumatologist, both in the Primary Care Centers and the Hospital Universitario de Canarias (HUC). 25-OH vitamin D values were gathered from 2662 blood samples from a total of 2635 patients, from September to November of 2018 (2241 from Primary Care and 421 from rheumatology). In order to determine the use of calcium and vitamin D supplements, and the presence of bone pathology, either renal or from a malabortive process, 400 individuals were randomized (250 from primary care and 150 from rheumatology. Demographic data (age and gender), calcium serum, phosphor and $25-\mathrm{OH}$ vitamin D levels were gathered for the individual records. With regards to the treatment, data about vitamin $\mathrm{D}$ supplements, calcium with vitamin $\mathrm{D}$, or the sum of both, that the patient may have in electronic prescriptions at that time; as well as osteoporosis treatment (biphosphonates, denosumab or teriparatide) were gathered.

Results: Using the age, gender, male/female relation, the levels of vitamin D, calcium and phosphor, as comparison factors; the characteristics of the random population were statistically indistinguishable from the global population. Regarding the random sample characteristics, from the 150 rheumatology patients, 11 were men $(7.3 \%)$ and 139 women $(92.7 \%)$. While from the 250 primary care patients, 66 were men $(26.4 \%)$ and 184 were women $(73.6 \%)$. The average age of the primary care sample was $55.76 \pm 19.72$ years and $65.16 \pm 13.84$ years in the rheumatology sample.

In the total random healthy population: without bone pathology, renal or malabortive and without calcium, vitamin $D$ or antiresorptive drug $(n=181)$ treatment, the levels of vitamin $D$ were $31 \pm 14 \mathrm{ng} / \mathrm{ml}$ with a normal distribution and without clear differences between the primary care and rheumatology patients. When the healthy population distribution was studied by vitamin $\mathrm{D}$ levels, the $55 \%$ presented values below $30 \mathrm{ng} / \mathrm{ml}, 12 \%$ below $20 \mathrm{ng} / \mathrm{ml}$ and $4 \%$ showed levels under $12.5 \mathrm{ng} / \mathrm{ml}$ : levels agreed as deficient (see graph).

Conclusion: The $55 \%$ of the patients studied in primary care and rheumatology, without renal, digestive or bone disease and without vitamin D supplement, 
presented vitamin levels below the actual limits of $30 \mathrm{ng} / \mathrm{ml}$. These limits, used by most of the laboratories, tend to overestimate the vitamin $\mathrm{D}$ deficiency. References:

[1] Manson, JE. N Engl J Med 2018, DOI: 10.1056/NEJMoa1809944.

[2] Spector, TD. BMJ 2016: 355: i6183

[3] Wu, F. Osteoporosis International 2017; 28: 505-515.

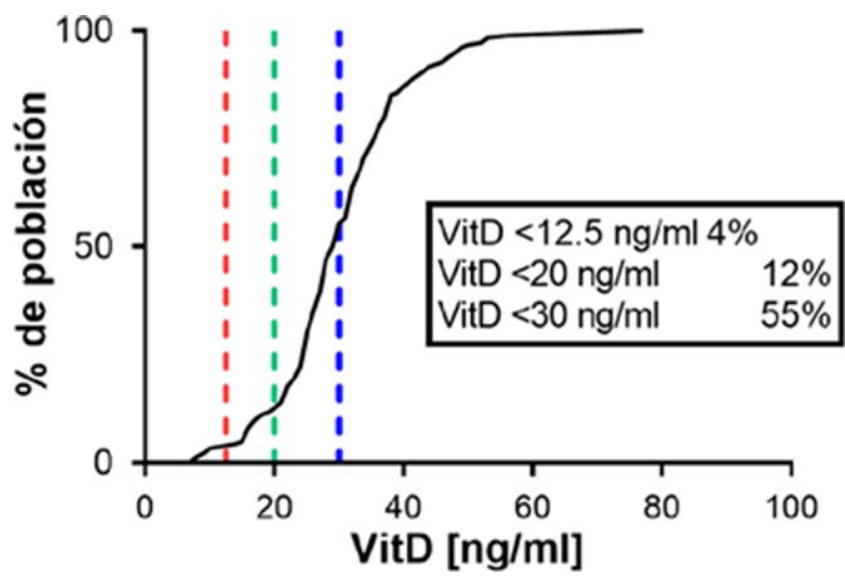

Disclosure of Interests: None declared

DOI: 10.1136/annrheumdis-2020-eular.4796

\section{AB0904 \\ PERSISTENCE AND REASONS FOR DISCONTINUATION OF DENOSUMAB IN PATIENTS WITH RHEUMATOID ARTHRITIS}

S. Mizuki ${ }^{1}$, T. Kai2, K. Mishima3, H. Ikeuchi3, K. Oryoji3. ${ }^{1}$ Matsuyama Red Cross Hospital, The Center for Rheumatic Diseases, Matsuyama, Japan; ${ }^{1}$ Matsuyama Red Cross Hospital, The Center for Rheumatic Diseases, Matsuyama, Japan; ${ }^{1}$ Matsuyama Red Cross Hospital, The Center for Rheumatic Diseases, Matsuyama, Japan

Background: Denosumab, a fully human monoclonal antibody to receptor activator of nuclear factor kappa B ligand, which inhibits osteoclast differentiation, activation and survival, not only increases bone mineral density but also inhibits the progression of bone erosion in patients with rheumatoid arthritis $(R A)^{1-3}$ ) Therefore, denosumab have been preferably prescribed for patients with RA recently. The persistence with denosumab, which is administered subcutaneously once every 6 months, was reported higher than with oral bisphosphonates ${ }^{4)}$, and in the prospective cohort studies, the persistence rate for one year was reported to be $82-95 \%{ }^{5-6)}$. However, there have been no report about the persistence in patients with RA treated with denosumab, moreover the reasons for discontinuation of denosumab.

Objectives: The aims of this single center retrospective cohort study were 1) to assess the persistence with denosumab in a routine clinical setting and 2) to identify the reasons of discontinuation in patients with RA. And we also reviewed the clinical outcomes of osteonecrosis of the jaw in patients with RA during denosumab treatment.

Methods: The present study is based on databases from our hospital, which include age, gender, date of injection of denosumab, as well as information on patients' characteristics. Patients were included in this study when denosumab were newly started at our department during the period from June 1, 2013 and September 30, 2017. In this study, persistence was defined as patients with an interval between injections of no longer than 6 months plus 8 weeks. Patients were followed until censoring (death, transferring to another hospital) or the end of the study (August 3, 2018).

We investigated reasons for the discontinuation of denosumab. Major reasons for the discontinuation of denosumab were classified as adverse event, anxiety over adverse events, patient's transfer or request, doctor's careless lack of refilling an injection, and other reason

We identified patients who had been diagnosed as osteonecrosis of the jaw, and demographic, pharmacological, and clinical data were collected from medical records.

Results: One hundred and seventy-five patients were identified. KaplanMeier analysis showed a slow decline of persistence after initiating denosumab therapy, dropping to 80.4 and $61.9 \%$ after 1 and 2 years of follow-up. When analyzing the reason of discontinuation as adverse events, the persistence rate of denosumab was at 89.4 , and $79.4 \%$ at 1 , and 2 years of follow-up, respectively.

During 2-year period, 72 patients discontinued denosumab. A total of 27 adverse events occurred, of which five events were osteonecrosis of the jaw. The other reasons for adverse event included death in four, fracture in three, and so on. Six patients discontinued due to anxiety over dental adverse event. Thirteen patients were in doctor's careless lack of refilling an injection

All five patients who were diagnosed as osteonecrosis of the jaw had received the treatment with prednisolone, and four were treated with biologic drugs. All patients stopped denosumab and switched to other drugs including teriparatide. All patients underwent surgical curettages of necrotic bone and cured.

Conclusion: Persistence of denosumab in patients with RA is comparable to that in postmenopausal women with osteoporosis. Dental screening and care should be important to continue denosumab treatment.

References:

[1] Cohen SB. Arthritis Rheum. 2008;58:1299-1309.

[2] Takeuchi T. Ann Rheum Dis. 2019;78:899-907.

[3] Ebina K. Osteoporos Int. 2018;29:1627-1636.

[4] Hadji P. Osteoporos Int. 2016;27:2967-2978.

[5] Silverman SL. Arch Osteoporos. 2018;13:85. doi:10.1007/s11657-018-0491-z [6] Hadji P. Osteoporos Int. 2015;26:2479-2489.

Disclosure of Interests: Shinichi Mizuki Speakers bureau: AbbVie, Asahi Kasei Chugai, Eli Lilly, Janssen, Mitsubishi Tanabe, Ono, Tatsuya Kai: None declared, Koji Mishima: None declared, Hiroko Ikeuchi: None declared, Kensuke Oryoji: None declared

DOI: 10.1136/annrheumdis-2020-eular.782

\begin{tabular}{|l|l}
\hline AB0905 & THE PREVALENCE AND RISK FACTORS OF \\
OSTEOPOROSIS IN PATIENTS WITH INFLAMMATORY \\
BOWEL DISEASES: A TUNISIAN STUDY
\end{tabular}

L. Mnif $^{1}$, H. Gdoura ${ }^{1}$, L. Chtourou ${ }^{1}$, A. Amouri ${ }^{1}$, M. Boudabbous ${ }^{1}$, N. Tahri ${ }^{1}$. ${ }^{1}$ University Hospital Hédi Chaker, Gastroenterology, Sfax, Tunisia

Background: Osteoporosis is as known a chronic complication of inflammatory bowel diseases (IBD). Its etiopathogenesis is often multifactorial.

Objectives: The aim of our study was to describe the prevalence of reduced bone mineral density and to identify risk factors of osteoporosis in patients with inflammatory bowel diseases.

Methods: This is a retrospective study over three years, collecting patients suffering from IBD and having benefited from a bone densitometry. We have specified for each patient the clinical data and the IBD characteristics. Bone minera density (BMD, g/ cm) was assessed by dual X-ray absorptiometry. Osteoporosis was diagnosed when BMD was 2.5 standard deviations below the mean peak value in young adults ( $T$ score,22.5 SD). Patients with other pathology that may change the bone metabolism were excluded.

Results: sixty-one patients were included with an average age of $38 \pm 13$ years [16-73]. The sex ratio M / F was 1.25 . $69 \%$ of patients had ulcerative colitis. The bone density profile was normal in $49.2 \%$ of the cases. Osteoporosis and osteopenia were noted in $13.1 \%$ and $37.7 \%$ of patients, respectively. Osteoporosis was associated with advanced age $(50.5 \pm 16.5$ years vs $36.26 \pm 12.93$ years $p=0.007)$ and longer course disease $(6.75 \pm 7,4$ years vs $2.5 \pm 4$ years; $p$ $=0.015)$. The cumulative dose of prednisone equivalent used in patients with osteoporosis was significantly higher than the other patients $(2775 \pm 3338 \mathrm{mg}$ vs $706 \pm 1449 \mathrm{mg} ; \mathrm{p}=0.003)$. Osteopenia was more frequently associated with crohn's disease ( $58 \%$ vs $28.6 \% p=0.0029)$. There was no significant difference between the group with osteoporosis or osteopenia and the group with normal bone densitometry for sex and body mass index.

Conclusion: Osteoporosis during IBD is associated with advanced age, longer duration of illness and administration of high doses of corticosteroids. The high proportion of osteoporosis and osteopenia in our study underlines the importance of systematic BMD measurement in all IBD patients as a base for initiating the appropriate treatment

References:

[1] The prevalence and risk factors for osteoporosis in patients with inflammatory bowel disease. Miznerova E et al. Bratisl Lek Listy. 2013;114(8):439-45.

[2] Osteoporosis and inflammatory bowel disease: prevalence and risk factors in Tunisian patients. Boubaker J et al. Gastroenterol Clin Biol. 2003 Oct;27(10):901-7.

Disclosure of Interests: None declared

DOI: 10.1136/annrheumdis-2020-eular.1878

\section{AB0906 \\ PREVALENCE OF HYPOVITAMINOSIS D IN DIAGNOSTIC PATIENTS OF BREAST NEOPLASIA IS GREATER THAN EXPECTED FOR THE GENERAL POPULATION? SERIES OF 200 DIAGNOSTIC PATIENTS OF BREAST NEOPLASIA IN A TERTIARY HOSPITAL INITIATING TREATMENT WITH AROMATASE INHIBITORS}

D. Montero $^{1}$, O. Ibarguengoitia ${ }^{1}$, L. Vega ${ }^{1}$, C. García ${ }^{1}$, J. M. Blanco ${ }^{1}$, M. E. Ruiz ${ }^{1}$, A. R. Inchaurbe ${ }^{1}$, O. Fernandez ${ }^{1}$, I. Calvo ${ }^{1}$, C. E. Perez ${ }^{1}$, M. L. García Vivar $^{1}$, E. Cuande ${ }^{1}$, E. Galindez ${ }^{1}$, A. Bilbao ${ }^{2}$, I. Torre ${ }^{1} .{ }^{1}$ Basurto University 